\title{
A Test for Understanding Simple Fractions Among 5th Grade Students at the Beginning of Lower Secondary Education
}

\author{
Tímea Karika $^{1}$ (D), Csaba Csíkos ${ }^{2 *}$ \\ 1 Doctoral School in Mathematics, ELTE Eötvös Loránd University, HUNGARY \\ 2 Department of Educational Evaluation and Planning, University of Szeged, HUNGARY
}

Received 6 October 2021 • Accepted 8 December 2021

\begin{abstract}
In this research, a new test for understanding simple fractions has been developed for students at the beginning of lower secondary education. In many countries, mathematics education in Grade 5 builds on elementary students' developing concepts of fractions. Understanding fractions causes many difficulties for students, and research on mental representations of fractions suggests that different visualizations may be helpful in teaching and learning. The sample consisted of 124 $5^{\text {th }}$-grade students, and the reliability of the test proved to be high (alpha=.95). Out of the three types of visualization, the pie chart was the easiest to recognize, and $\frac{1}{2}$ (half) proved to be the easiest, and $\frac{1}{3}$ (one-third) the most difficult to be recognized. The type of visualization has a stronger effect on students' performance than the type of fraction (unit versus non-unit fractions). Most surprisingly, students were better at recognizing $\frac{2}{4}$ and $\frac{2}{3}$ than their unit fraction counterparts, $\frac{1}{2}$ and $\frac{1}{3}$. The test was supplemented by questions on attitude towards learning fractions.
\end{abstract}

Keywords: fractions, visualization, lower secondary students

\section{INTRODUCTION}

Conceptual understanding of fractions is among the greatest challenges in mathematics classes students face during their school years, while the topic is of utmost importance for later success in mathematics (Torbeyns et al., 2015). Fractions are difficult to understand not only in primary and lower secondary schools, but also for upper secondary and university students, and for adults as well (Kerslake, 1986; Merenluoto \& Lehtinen, 2002; Vamvakoussi et al., 2012). Understanding fractions is a necessary prerequisite knowledge item for understanding rational numbers and those branches of school mathematics that rely on rational numbers (for instance, algebraic equations, see Kieren (1993)).

The difficulties concerning the conceptual understanding of fractions have been addressed by many scholars (e.g., Vamvakoussi et al., 2012; Vosniadou $\&$ Verschaffel, 2004). There may be at least three sources of difficulties identified. (1) Understanding non-unit fractions based on the conceptual understanding of unit fractions; (2) building connections between fraction names and mental representations, and (3) connecting fractions to other fields of mathematics, such as arithmetic, proportional reasoning, and geometry. As Karika and Csíkos (2018) revealed, there may be a gap between the elementary and lower-secondary grades (which are grade 4 and grade 5 in many countries) with respect to the actual development of the fraction concepts and the assumptions lower-secondary mathematics teachers and lower secondary textbooks held. After the slow and playful fostering of the conceptual understanding of fractions in the elementary school years, grade 5 textbooks may expect children to understand non-unit fractions as both the multiples of unit fractions and the quotient of two integers. In sum, in grade 5 teaching fractions may be built on exaggerated expectations about what students already learned in previous years.

The importance and the relevance of the unit fractions in the elementary school years (i.e., when the numerator is 1) have been extensively revealed and emphasized (see Kieren, 1983; McMullen et el., 2015; Streefland, 1984). The development of the concept of unit 


\section{Contribution to the literature}

- A short simple online test of understanding fractions has been developed. The test has excellent reliability.

- The test consists of both unit and non-unit fractions and three types of visualizations are covered: rectangular, pie chart, and horizontal bar. The relative importance of the type of visualization and the type of fractions (unit versus non-unit fractions) have been revealed.

- Students' attitude towards fractions learning proved to be somewhat ambiguous: they do not see why fractions are useful, but they agree that learning fractions are important.

fractions is a necessary prerequisite for learning non-unit fractions. Among the unit fractions, it is the $\frac{1}{2}, \frac{1}{3}$ and $\frac{1}{4}$ that are first understood even by many kindergarten children (Hunting \& Davis, 1991), and it is the $\frac{1}{2}$ alone that is confidently known by the age of 10 , and the development of the concept of other unit fractions are still in progress at that age (Hunting \& Korbosky, 1984). In line with this, these three most important unit fractions were assessed in Zhang et al.'s (2015) investigation.

In mathematics education practice, teaching unit fractions always precedes the teaching of non-unit fractions. In fact, by the end of the elementary school years, children are expected to compose non-unit fractions as multiples of unit fractions (Karika \& Csíkos, 2018). In a recent review, Braithwaite and Siegler (2021) claim that both non-unit fractions and the addition of two unit fractions are based on concatenating unit fractions, i.e., putting the mental representations of unit fractions together. Furthermore, understanding unit fractions is prerequisite knowledge for understanding proportional reasoning (Norton, 2006).

The mental representation of fractions follows a similar pattern to that of whole numbers (Schmithorst \& Brown, 2004). Therefore, the concept of fractions is based on three pillars: the number word of the fraction, the written fraction number itself, and the corresponding mental representation. Since writing numerals (including fractions) is a target achieved in the school years, the development of the concept of fractions from the kindergarten years depends on the connection between fraction names (number words, like half, third, etc.) and a corresponding mental representation. Among the possible mental representations, the visual representations arising from continuous quantities are of special importance.

According to Deringol's (2019) research, both preservice and in-service teachers are well aware of the importance of using visual representations, what is more, it is the topic of fractions where the importance and the power of visual representations become so obvious. In Tunc-Pekkan's (2015) study, different visual representations were examined: rectangular, pie chart, and mental number line. $4^{\text {th }}$ and $5^{\text {th }}$-grade students performed very well on tasks requiring them to write down the fractions $\frac{1}{4}$ and $\frac{1}{5}$ when given a rectangle or pie chart representation, however, they had difficulties to recognize $\frac{1}{3}$ when given a number line representation. In this study, both directions (fraction recognition from the shaded diagram, and shading a diagram from a given fraction) were used, and the students' performance was weaker when they had to construct the answer as a drawing as compared to constructing the answer as a numeral. Similar arrangement, i.e., fraction recognition from a shaded rectangle and shading a rectangle according to a given fraction can be found in Wong et al.'s (2006) research. In Sari et al.'s (2012) study these two directions were also present, and they found the two ways of fraction understanding equally well mastered.

According to Cady et al. (2015), there are several kinds of diagrams in the textbooks to help students learning fractions. Two basic types are the area and the length models. While rectangles and pie charts of the area type representations, the number line, and the horizontal bar graphs are of the length type diagram. As Cady et al. rightly claim, within the realm of the length models, it is a different and more difficult task for children to place numbers to a number line than comparing two lengths given horizontally. In an intervention study among at-risk students (Fuchs et al., 2013), both area models (fraction tiles and fraction circles) and the number line model were used.

Learning fractions have several connections to learning other fields of mathematics. In international educational surveys, e.g., IEA and PISA studies, fractions are part of arithmetic. However, due to the visual representations which are essentials in the development of the concept of fractions, also geometry also includes relevant components for learning fractions. Students' attitudes, nevertheless, may be in connection with their math performance (Mata et al., 2012), and especially with their learning of fractions.

According to Fonseca's (2012) conceptual analysis, we consider students' attitudes toward learning fractions a unidimensional construct that can be compared to other math-related attitudes. In that way, it becomes possible to reveal whether the attitude towards learning fractions is strongly connected to performance on a test of fractions.

In this study, the following research problems were examined. 
1. Development of a short online test on lower secondary school students' knowledge on fractions, enabling both norm-referenced and criterion-referenced evaluation.

2. How do different visual representations help or hinder students' understanding of fractions?

3. What is the relative importance of the visualization form and the magnitude of the numerator in understanding fractions?

\section{METHOD}

\section{Participants}

The paper-and-pencil version of the test was piloted in Grahamstown, South Africa, among thirty $5^{\text {th }}$ grade elementary school children. There were 124 students involved in the current data analysis from four Hungarian schools. The participants of the current study attend schools with 4 mathematics classes per week, and-in accordance with the Hungarian tradition of subject-special teaching from grade 5, the children were taught by mathematics teachers of lower secondary schooling. In grade 5 , the topic of fractions is a relevant curricular target, and the teacher can and should build on the concept of fractions developed in grades 3 and 4 . In most schools, there is a leveling, repetition part on fractions before starting the systematic teaching of the grade 5 learning material. Since the current study aimed to evaluate the consolidated, elementary school level knowledge of students, the participants in the recruited schools were in the preceding phase of the grade 5 learning material of fractions.

\section{Measures}

According to Cady et al. (2015) and Tunc-Pekkan (2015), the conceptual understanding of fractions may depend on the types of visualization used in both the classroom practice and in the test used for measuring the level of understanding. The triple code model also valid for fractions further suggests measuring at least two directions, i.e., from numbers to visual representations and vice versa (The third link in the triple code model, namely, the connection between the number words and the written numbers has not been addressed in this investigation). Furthermore, since the distinction between unit fractions and non-unit fractions is often apparent in the teaching practice, and understanding the latter presupposes the understanding of unit fractions, we included both types of ordinary fractions in the test.

The online test administered in the current study was developed based on the experiences of the paper-andpencil pilot test. The experiences of the pilot test were used in two ways: only fractions less than 1 were involved, and besides the two original modes of visualizations (rectangle and pie chart), a third one was added. Because of unforeseen circumstances caused by the COVID-19 virus, the new test version was administered online, thus the originally planned comparison of children's conceptual understanding of fractions in two countries must have been disregarded.

The online test consisted of 30 items; all of them were of the multiple-choice format enabling quick and objective scoring and data analysis. The kinds of visual representations were used, each comprising 10 items. The structure of the test was as follows (please consult the Appendix A for the actual and detailed formal appearance of the items).

1. Three times six items with rectangular, pie chart and horizontal bar graph items for the following six fractions: $\frac{1}{2} ; \frac{1}{3} ; \frac{2}{3} ; \frac{1}{4} ; \frac{3}{4} ; \frac{2}{4}$. In these items, students were required to select the appropriate visual representation for the specified fraction.

2. Three times four items with rectangular, pie chart and horizontal bar graph items, where the visual representation is provided, and students had to select the corresponding fractions for $\frac{1}{4}, \frac{1}{2}, \frac{1}{3}$, and $\frac{2}{3}$.

Additionally, students were asked to answer five questions of the Likert-scale type about their attitude towards mathematics, geometry and fractions, and their opinion on the usefulness and importance of learning fractions.

\section{RESULTS}

\section{Reliability}

Since one of our aims was to develop a highreliability test for measuring the level of knowledge on fractions at the beginning of the lower secondary schooling, it is important to examine the reliability of the test. The Cronbach-alpha estimation proved to be very high indicating a good level of reliability for the overall test $(\alpha=.948)$. Further analysis of reliability was conducted using the "scale if item deleted" option. By means of this analysis, the reliability estimations still remained in the .943-.948 interval, indicating that all the test items make an appropriate contribution to the overall reliability.

\section{Descriptive Statistical Analyses}

We start presenting the results with the basic quantitative characteristics of the test. Due to the normreferenced assessment approach, it is important to present first the mean values for the overall test and for the items and sub-tests. The overall percentage of the correct solutions was 77.4 indicating that the test proved to be fairly easy and solvable for the students. The percentage of the correct solutions to the first 18 test items are presented in Table 1 . In these items, students had to match the corresponding geometrical figure for the specified fraction. Besides the individual items, the solution rate for the groups of items are also shown. 
Table 1. Rate of correct solutions for the first 18 test items

\begin{tabular}{lccccccc}
\hline & $\frac{1}{2}$ & $\frac{1}{3}$ & $\frac{2}{3}$ & $\frac{1}{4}$ & $\frac{2}{4}$ & $\frac{3}{4}$ & Overall \\
\hline Rectangular & $81 \%$ & $66 \%$ & $69 \%$ & $66 \%$ & $79 \%$ & $90 \%$ & $75 \%$ \\
Pie chart & $92 \%$ & $71 \%$ & $90 \%$ & $85 \%$ & $91 \%$ & $91 \%$ & $87 \%$ \\
$\begin{array}{l}\text { Horizontal } \\
\text { bar graph }\end{array}$ & $88 \%$ & $66 \%$ & $68 \%$ & $66 \%$ & $71 \%$ & $73 \%$ & $72 \%$ \\
Overall & $87 \%$ & $68 \%$ & $76 \%$ & $72 \%$ & $80 \%$ & $85 \%$ & \\
\hline
\end{tabular}

Table 2. Rate of correct solutions for the 19-30 test items

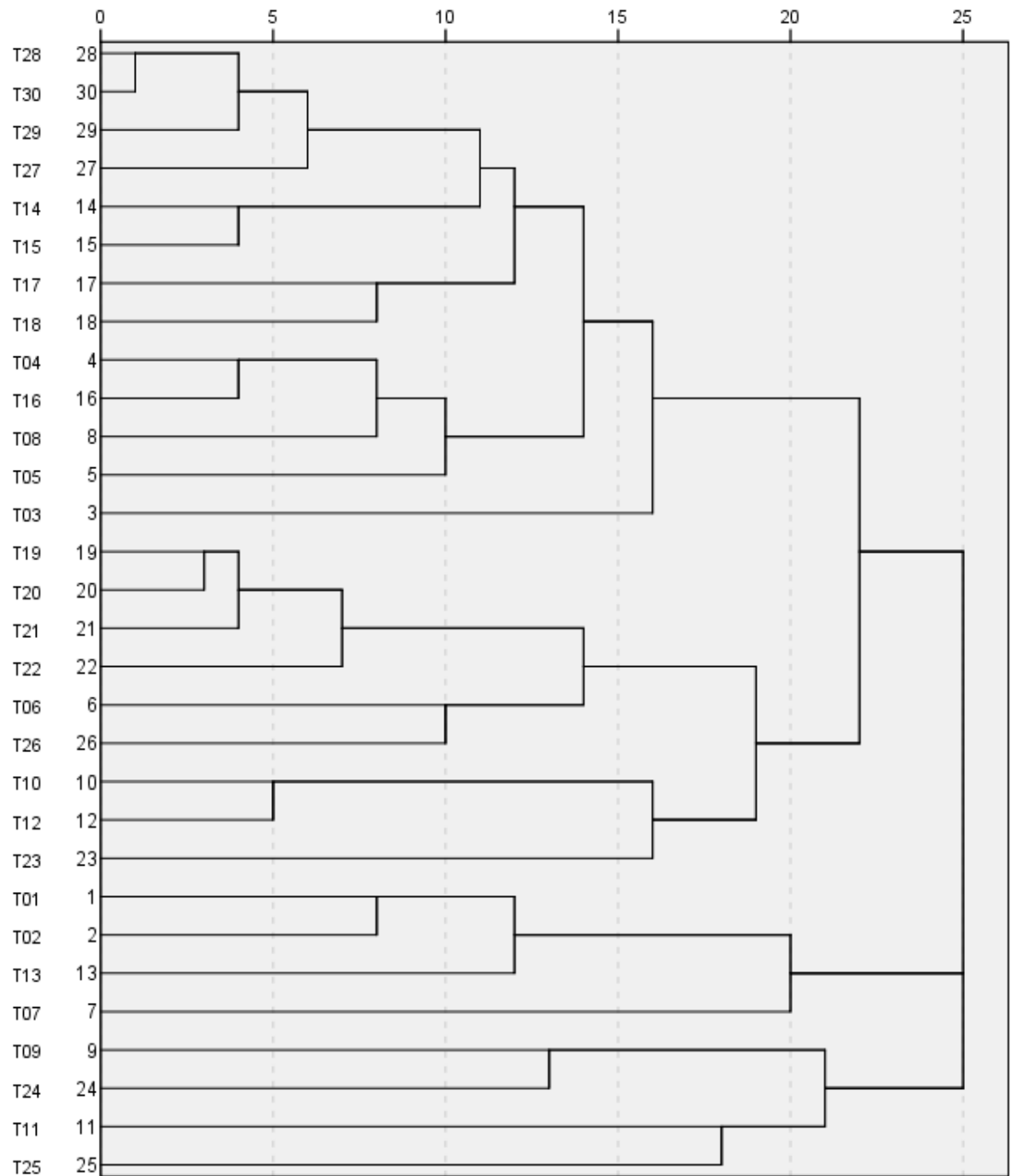

Figure 1. Dendrogram of the items yielded from cluster analysis with Pearson-correlations and the furthest neighbor clustering method

The results suggest that $\frac{1}{2}$ is the easiest, and $\frac{1}{3}$ is the most difficult to recognize, while it is the pie chart diagram type that was handled most successfully.

As for the items where students had to select the fraction from the shaded geometrical figures, Table 2 presents the rates of correct solutions.

The structure of the test can be nicely visualized through hierarchical cluster analysis on the test items. Figure 1 presents the dendrogram yielded by Pearsoncorrelation measures and the furthest neighbor clustering method. According to the significance test of the correlation indexes, the scale from 0 to 25 indicates

\begin{tabular}{lccccc}
\hline & $\frac{1}{4}$ & $\frac{1}{2}$ & $\frac{1}{3}$ & $\frac{2}{3}$ & Overall \\
\hline Rectangular & $76 \%$ & $73 \%$ & $74 \%$ & $74 \%$ & $74 \%$ \\
Pie chart & $91 \%$ & $92 \%$ & $92 \%$ & $81 \%$ & $89 \%$ \\
Horizontal & $64 \%$ & $69 \%$ & $67 \%$ & $66 \%$ & $67 \%$ \\
bar graph & & & & & \\
Overall & $77 \%$ & $78 \%$ & $78 \%$ & $74 \%$ & \\
\hline
\end{tabular}


Table 3. Items with the highest explained variance on the total score as revealed by stepwise regression analysis

Item

21. What proportion of the rectangle is colored?

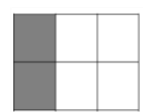

14. Which picture shows that $\frac{1}{3}$ (third) of the ribbon is colored?

18. Which picture shows that $\frac{3}{4}$ of the ribbon (three quarters) is colored?

2. Which picture shows that $\frac{1}{3}$ (third) of the rectangle is colored?

10. Which picture shows that $\frac{1}{4}$ (quarter) of the circle is colored?
Correct answer

$\frac{1}{4}$
$\frac{1}{3}$

$\frac{1}{3}$
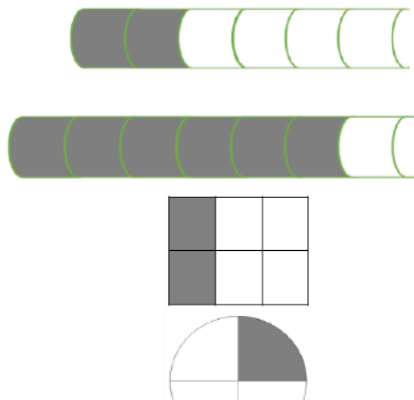

Table 4. The role of different types of visualizations as revealed by regression analysis (Dependent variable: Total score)

\begin{tabular}{lccc}
\hline Independent variables & $\mathrm{r}$ & Beta & Explained variance, $\mathrm{r}^{*}$ Beta(\%) \\
\hline Rectangular chosen from fraction & .850 & .230 & 19.5 \\
Pie chart chosen from fraction & .775 & .165 & 12.8 \\
Bar graph chosen from fraction & .910 & .265 & 24.1 \\
Fraction chosen from rectangular & .829 & .198 & 16.4 \\
Fraction chosen from pie chart & .728 & .102 & 7.4 \\
Fraction chosen from bar graph & .905 & .217 & 19.7 \\
& & & $\Sigma=100$ \\
\hline
\end{tabular}

Note. SE for all coefficients were 0

The structure of the test was analyzed also by means of stepwise regression analysis. With this technique, the items with the highest level of explained variance can be revealed. Since the overall performance level was fairly high, it becomes important to know which items could distinguish between the students, i.e., those items that explain the differences in the overall performance. With the total score of the test as the dependent variable and with the items as independent variables, we found six items explaining more than $95 \%$ of the variance of the total score. Table 3 shows the items with the highest explained variance.

Since the six items presented in Table 3 explains more than $95 \%$ of the total score, it means that in case of normreferenced evaluation, these six items can form a shortened version of the whole test holding almost the same level of information about the differences between students' knowledge level on the original test.

\section{The Role Visualization and the Magnitude of the Numerator Play in Understanding Fractions}

We have already presented the rate of correct answers on items with different types of visualizations and with different numerators previously. In Table 4, we present the results of the regression analysis to reveal the role of different visualization types.

Table 4 indicates that the bar graph diagrams (both versions, i.e., either when the fraction is given, and the student has to find the corresponding pie chart; or when the shaded pie chart is given, and the student has to find the corresponding fraction) hold the largest part of explained variance. The pie chart diagrams represent much less part of the explained variance, due to the ceiling effect in the rate of correct solutions (see Table 1 and Table 2). The role of visual representations is consistent on the first 18 items (the fraction is given) and the next 12 items (the shaded diagram is given).

As for the role of the numerator, we examined the first 18 items, since half of them contained fractions with 1 as numerator and half of them contained 2 or 3 as numerators. Table 5 presents the results of regression analysis with the total score on the first 18 items as the dependent variable.

\section{The Relative Importance of Visualization and the Magnitude of the Numerator in Students' Performance}

Both the type of visualization and the magnitude of the numerator was investigated previously, and both 
Table 5 . The role of the numerator as revealed by regression analysis (Dependent variable: Total score)

\begin{tabular}{lccc}
\hline Independent variables & $\mathrm{R}$ & Beta & Explained variance, $\mathrm{r}^{\star}$ Beta $(\%)$ \\
\hline Fractions with 1 as numerator & .963 & .578 & 55.7 \\
Fractions with 2 or 3 as numerator & .944 & .470 & 44.3 \\
& & & $\Sigma=100$
\end{tabular}

Note. All Beta values are significant $(\mathrm{p}<0.001)$

Table 6. Students' attitude towards mathematics, geometry, and fractions

\begin{tabular}{lccc}
\hline & $\mathrm{N}$ & Mean & SD \\
\hline I like mathematics. & 123 & 3.88 & 1.03 \\
I like fractions. & 122 & 3.57 & 1.19 \\
I like geometry. & 124 & 3.94 & 1.22 \\
Learning fractions is useful. & 123 & 2.32 & .62 \\
Learning fractions is important. & 124 & 4.13 & 1.10 \\
\hline
\end{tabular}

factors affect students' performance on the test. Now we analyze these two factors together. Two-way ANOVA is the appropriate method to be conducted with two repeated-measures factors. The analysis again is restricted to the first 18 items. According to the withinsubject two-way ANOVA, there is no significant interaction between these two factors, $\mathrm{F}(2,246)=1.46$, $p=.23)$. The types of visual representations have a significant effect on students' performance, $\left.\mathrm{F}(2,246)=43.17, \mathrm{p}<.001, \mathrm{\eta}^{2}=26.0 \%\right)$; while there is not no significant effect from the other factor, i.e., the magnitude of the numerator, $\mathrm{F}(2,246)=2.10, \mathrm{p}=.15$, $\eta^{2}=1.7 \%$.

\section{Students' Attitudes Towards Mathematics, Geometry, and Fractions}

Table 6 presents the descriptive statistics of students' answers to the five attitude questions. A five-point Likert scale was used, 5 is the most positive attitude, 3 is neutral, and 1 is the most negative standpoint.

Students have a generally positive attitude towards mathematics as a school subject and geometry as a field within mathematics. However, they have a significantly less positive attitude towards fractions as compared to mathematics itself (paired-samples t-test, $t(121)=3.60$, $p<.001$. While students acknowledge the importance of learning fractions, students have a negative opinion on the usefulness of learning fractions.

\section{Students' Attitudes and Their Performance}

The correlation coefficients between students' overall performance and their attitude variables range from 0.21 (usefulness of learning fractions) to 0.62 (attitude towards fractions). All these correlation coefficients are significant at the $p<0.05$ level. The magnitude and significance of the correlation coefficients proved to be similar for the groups of items examined in the previous sections with one notable exception. The attitude towards geometry had significant correlations with performance on the pie chart (.26) and bar graph (.22) items, but not with performance on the items with rectangles (.18).

\section{DISCUSSION}

\section{Novelty}

In this research, we have developed a short, highly reliable test on simple fractions that consists of both fraction-to-diagram and diagram-to-fraction items, and furthermore provides a systematic composition of unit fraction and non-unit fraction items. This test can be used for diagnostic purposes at the beginning of lower secondary education. Our test has some antecedents in previous investigations, e.g., Chahine (2011) applied pictorial-symbolic translation items in her test, but without publishing reliability and sample items.

\section{Main Findings}

With the first research question, we had a twofold objective: to develop a basic test for lower secondary students that has high reliability and can be used for diagnostic assessment purposes, while at the same time we also set a goal for providing a general picture about students' understanding of some simple fractions. The test proved to be highly reliable contrary to the possible ceiling effect due to the predominantly high-level performance students demonstrated. A cluster analysis on the test items nicely illustrated the overwhelmingly dominant role of visual representations in students' performance.

The research question concerned the different visual representations that may help or hinder students in understanding different fractions. Our research can be considered as an extension of Tunc-Pekkan's (2015) study who dealt with unit fractions only. According to our results, the visual representations used in the test had a significant effect on students' performance. It is the pie chart diagram type items on which we experienced the best performance. Out of the six fractions investigated, the $\frac{1}{2}$ proved to be the easiest and $\frac{1}{3}$ the most difficult to comprehend. This may be surprising, 
indicates that some non-unit fractions are easier to be recognized than their unit fraction counterpart.

Both the type of visual representation used and the magnitude of the numerator (whether it is 1 or not 1 ) had significant effects on students' performance. However, when these two factors were combined, the dominant role of visual representations was revealed. This may have been due to the findings that some non-unit fractions were easier to be recognized than their unit fraction counterpart. The possible explanations are twofold. First, for non-unit fractions, the metacognitive components of reasoning play their conscious and effortful roles, contrary to unit fractions which are handled more automatically. A second possible explanation would be that both $\frac{2}{4}$ and $\frac{2}{3}$ have been processed as number facts in students' minds, and not the multiplications of their unit fraction counterparts.

Students have a fairly negative opinion about the usefulness of learning fractions. In connection with this, they have a less positive attitude towards learning fractions than towards learning either geometry or mathematics as a whole. Nevertheless, they clearly see the importance of learning fractions.

\section{Educational Implications}

Since our test is of primarily diagnostic nature, both group-level and individual profiles can be defined and determined. According to our results, the importance of the so-called multimodal approach is advocated, i.e., several different kinds of visual representations should be matched with fraction numerals and number words in order to strengthen the associations between three brain regions responsible for processing and understanding fractions. In both directions, i.e., from number words to diagrams, and from diagrams to number words, the connections should be strengthened by presenting various visual representations. Our results suggest that besides unit fractions, some non-unit fractions can be processed as independent representations which means that for instance $\frac{2}{3}$ can be represented not as a concatenation of two $\frac{1}{3}$, but "in its own right", building immediate connections between the visual representation of the fraction (rectangle, pie chart or other kinds) and the fraction name.

Teachers should advocate and encourage the use of different visual representations in fraction learning. However, Zhang et al. (2015) warn that area-model representations should not be the only or the preferred visual representation type used in the school, since it may restrict students' approaches in various problemsolving situations. In line with what Fazio and Siegler (2011) proposed, prospective elementary and secondary teachers should be trained to how to use visual representations effectively, depending on the nature of the mathematical concepts (e.g., shaded diagrams are useful to illustrate word problems on cutting something into equal pieces), and depending on the individual differences and developmental pathways.

The test was administered in grade 5 just some weeks before students started to learn fractions, therefore the test diagnostically assessed their prerequisite knowledge, and provided information about both their individual performance profiles and their class-level average achievement. According to the actual results obtained by the students, teachers can adjust their decisions as how to best help them in the development of their conceptual understanding. Since-at least in Hungary-grade 5 students are generally taught by a subject specialist mathematics teacher, whereas they were taught in grade 4 by their subject generalist elementary teacher, it is important and fruitful to start teaching fractions with using diagnostic assessment tools like the current on-line test in our investigation. If and only if students have a sound conceptual understanding of fractions in terms of quick and confident translation between visual and symbolic representation, will then further tasks such as operations with fractions be meaningful and efficient.

\section{Limitations and Further Research Questions}

Much more information could have been gained if time was measured for each individual task. The reaction time to each individual task would give information about the speed of the recognition. Furthermore, eye-movement research would reveal the different individual strategies students have in recognizing different fractions. The main limitation of the current study comes from the brevity of the test. More comprehensive coverage of further fractions and representations may be address in a system of test versions administered to a much larger sample.

Author contributions: All authors have sufficiently contributed to the study, and agreed with the results and conclusions.

Funding: The research was supported by the MTA-SZTE Metacognition Research Group.

Acknowledgements: The authors would like to thank to Lise Westaway for organizing the pilot study in the framework of an Erasmus+ project funded by the European Union

Declaration of interest: No conflict of interest is declared by authors.

\section{REFERENCES}

Braithwaite, D. W., \& Siegler, R. S. (2021). Putting fractions together. Journal of Educational Psychology, 113(3), 556-571. https://doi.org/10.1037/ edu0000477

Cady, J. A., Hodges, T. E., \& Collins, R. L. (2015). A comparison of textbooks' presentation of fractions. School Science and Mathematics, 115(3), 105-116. https:/ / doi.org/10.1111/ssm.12108

Chahine, I. (2011). The role of translations between and within representations on the conceptual 
understanding of fraction knowledge: A transcultural study. Journal of Mathematics Education, $4(1), 47-59$.

Deringol, Y. (2019). Misconceptions of primary school students about the subject of fractions. International Journal of Evaluation and Research in Education, 8(1), 29-38. https:/ / doi.org/10.11591/ijere.v8i1.16290

Fazio, L., \& Siegler, R. (2011). Teaching fractions. educational practices series-22. UNESCO International Bureau of Education.

Fonseca, J. R. S. (2012). Students' attitudes toward math learning. In N. M. Seel (Ed.), Encyclopedia of the sciences of learning (pp. 3214-3219). Springer. https://doi.org/10.1007/978-1-4419-1428-6_1078

Fuchs, L. S., Schumacher, R. F., Long, J., Namkung, J., Hamlett, C. L., Cirino, P. T., Jordan, N. C., Siegler, R., Gersten, R., \& Changas, P. (2013). Improving atrisk learners' understanding of fractions. Journal of Educational Psychology, 105(3), 683-700. https:// doi.org/10.1037/a0032446

Hunting, R. P., \& Davis, G. E. (1991). Dimensions of young children's knowledge of the fraction one half ( $\mathrm{pp}$ 27-53). Springer. https://doi.org/10.1007/978-1-46123194-3_3

Hunting, R. P., \& Korbosky, R. K. (1984) Processes used to learn fractions. Report to the Academic Staff Development Committee, Western Australian Institute of Technology.

Karika, T., \& Csíkos, C. (2018). A törtfogalom fejlódésének segítése az alsó és a felsó tagozat határán [Fostering the concept of fractions at the boundary of primary and lower secondary school grades]. Gyermeknevelés Tudományos Folyóirat [Parenting Scientific Journal], 6(1), 86-98. https:/ / doi.org/10.31074/gyn201818698

Kerslake, D. (1986). Fractions: Children's strategies and errors. A report of the strategies and errors in secondary mathematics project. NFER-NELSON.

Kieren, T. E. (1983). Partitioning, equivalence, and the construction of rational number ideas. In M. Zweng (Ed.), Proceedings of the 4th International Congress on Mathematical Education (pp. 506-508). Birkhauser.

Kieren, T. E. (1993). Rational and fractional numbers: From quotient fields to recursive understanding. In T. P. Carpenter, E. Fennema, \& T. A. Romberg (Eds.), Rational numbers: An integration of research (pp. 49-84). Lawrence Erlbaum Associates.

Mata, M. D. L., Monteiro, V., \& Peixoto, F. (2012). Attitudes towards mathematics: Effects of individual, motivational, and social support factors. Child Development Research, 2012, Art. 876028. https:// doi.org/10.1155/2012/876028

McMullen, J., Laakkonen, E., Hannula-Sormunen, M., \& Lehtinen, E. (2015). Modeling the developmental trajectories of rational number concept(s). Learning and Instruction, 37, 14-20. https:/ / doi.org/10.1016/ j.learninstruc.2013.12.004

Merenluoto, K., \& Lehtinen, E. (2002). Conceptual change in mathematics: Understanding the real numbers. In M. Limon, \& L. Mason (Eds.), Reconsidering conceptual change: Issues in theory and practice (pp. 233-258). Kluwer.

Norton, S. (2006). Pedagogies for the engagement of girls in the learning of proportional reasoning through technology practice. Mathematics Education Research Journal, 18(3), 69-99. https://doi.org/10.1007/ BF03217443

Sari, E. A. P., Juniati, D., \& Patahudin, S. M. (2012). Early fractions learning of 3rd grade students in SD Laboratorium Unesa. Indonesian Mathematical Society Journal on Mathematics Education, 3(1), 17-28. https:// doi.org/10.22342/jme.3.1.617.17-28

Schmithorst, V. J., \& Brown, R. D. (2004). Empirical validation of the triple-code model of numerical processing for complex math operations using functional MRI and group Independent Component Analysis of the mental addition and subtraction of fractions. Neuroimage, 22(3), 14141420. https:// doi.org/10.1016/j.neuroimage.2004. 03.021

Streefland, L. (1984). Unmasking N-distractors as a source of failures in learning fractions. In B. Southwell, R. Eyland, M. Cooper, J. Conroy, \& K. Collis (Eds.), Proceedings of the Eighth Annual Conference of the International Conference for the Psychology of Mathematics Education (pp. 142-152). Mathematical Association of New South Wales.

Torbeyns, J., Schneider, M., Xin, Z., \& Siegler, R. S. (2015). Bridging the gap: Fraction understanding is central to mathematics achievement in students from three different continents. Learning and Instruction, 37, 513. https:// doi.org/10.1016/j.learninstruc.2014.03. 002

Tunc-Pekkan, Z. (2015). An analysis of elementary school children's fractional knowledge depicted with circle, rectangle, and number line representations. Educational Studies in Mathematics, 89, 419-441. https://doi.org/10.1007/s10649-0159606-2

Vamvakoussi, X., Van Dooren, W., \& Verschaffel, L. (2012). Naturally biased? In search for reaction time evidence for a natural number bias in adults. The Journal of Mathematical Behavior, 31(3), 344-355. https:/ / doi.org/10.1016/j.jmathb.2012.02.001

Vosniadou, S., \& Verschaffel, L. (2004). Extending the conceptual change approach to mathematics learning and teaching. Learning and Instruction, 14(5), 445-451. https://doi.org/10.1016/ j.learninstruc.2004.06.014 
Wong, M., Evans, D., \& Anderson, J. (2006). Developing a diagnostic assessment instrument for identifying students' understanding of fraction equivalence [Paper presentation]. The ACSPRI Social Science Methodology Conference, University of Sydney. http:/ / old.acspri.org.au/conference2006/proceed ings/streams / Paper\%2019\%20wong_monica_sub mitted.pdf

Zhang, X., Clements, M. K., \& Ellerton, N. F. (2015). Conceptual mis(understandings) of fractions: From area models to multiple embodiments. Mathematics Education Research Journal, 27(2), 233-261. https:/ / doi.org/10.1007/s13394-014-0133-8

\section{https://www.ejmste.com}




\section{APPENDIX A}

\section{The Actual and Detailed Formal Appearance of the Items}

1. Which picture shows $\frac{1}{2}$ (half) of the rectangle shaded?

a)

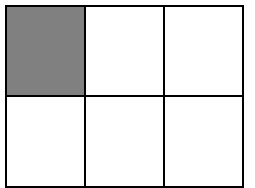

b)

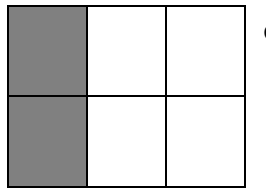

c)

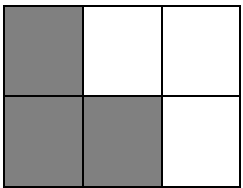

d)

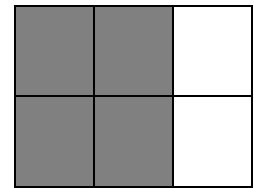

2. Which picture shows $\frac{1}{3}$ (one third) of the rectangle shaded?

a)

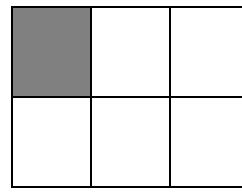

b)

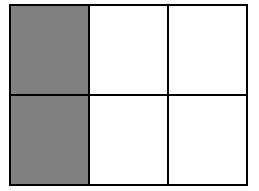

c)

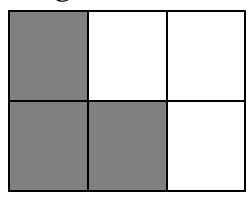

d)

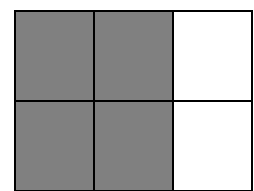

3. Which picture shows $\frac{2}{3}$ (two thirds) of the rectangle shaded?

a)

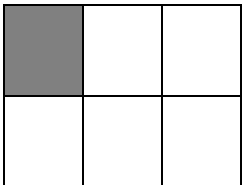

b)

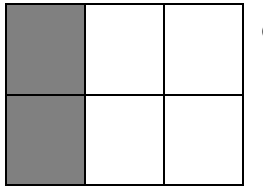

c)

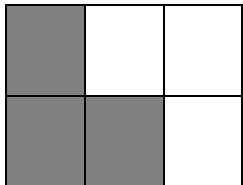

d)

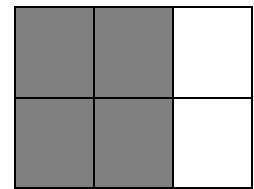

4. Which picture shows $\frac{1}{4}$ (one quarter) of the rectangle shaded?

a)

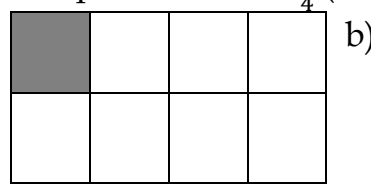

b)

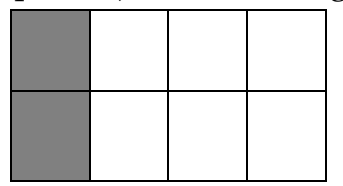

c)

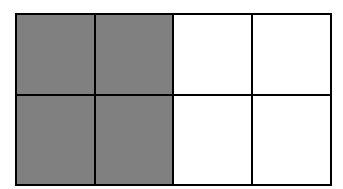

d)

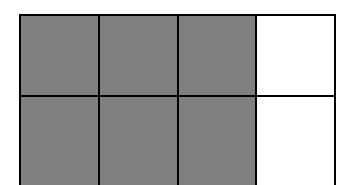

5. Which picture shows $\frac{2}{4}$ (two quarters) of the rectangle shaded?

a)

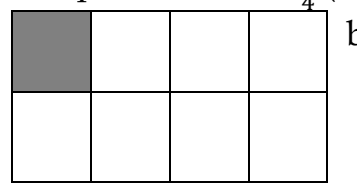

b)

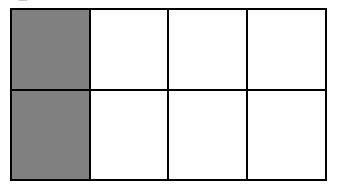

c)

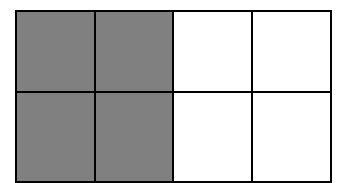

d)

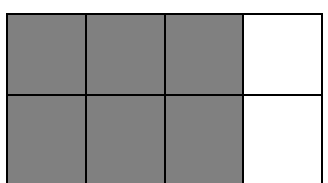

6. Which picture shows $\frac{3}{4}$ (three quarters) of the rectangle shaded?

a)

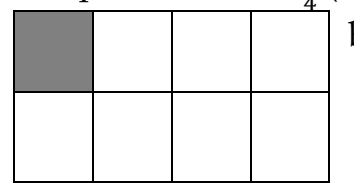

b)

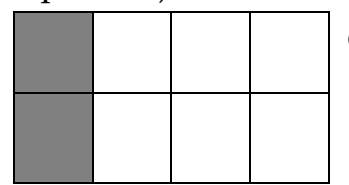

c)

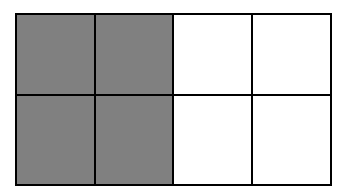

d)

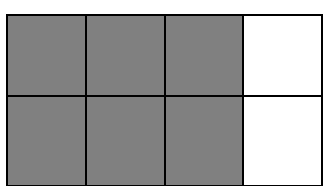

7. Which picture shows $\frac{1}{2}$ (half) of the circle shaded?

a)

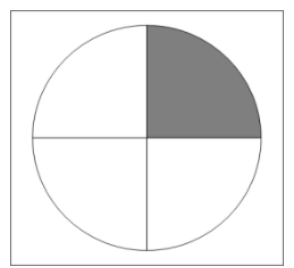

b)

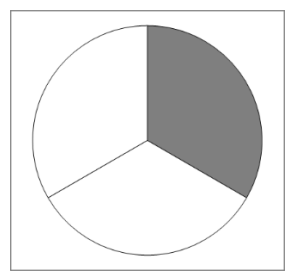

c)

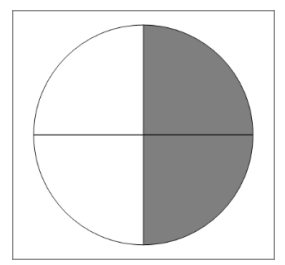

d)

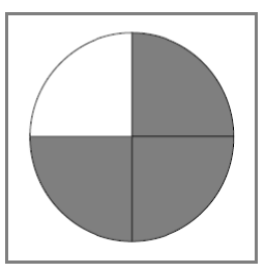


8. Which picture shows $\frac{1}{3}$ (one third) of the circle shaded?

a)

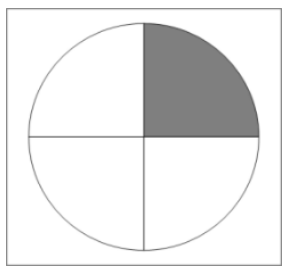

b)

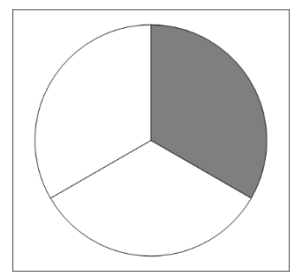

c)

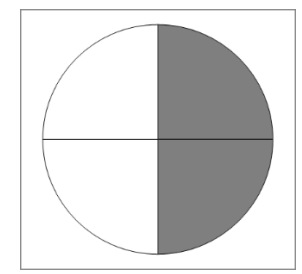

d)

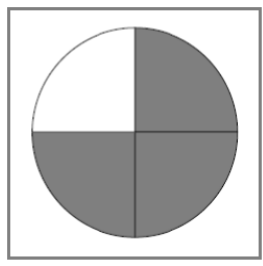

9. Which picture shows $\frac{2}{3}$ (two thirds) of the circle shaded?

a)

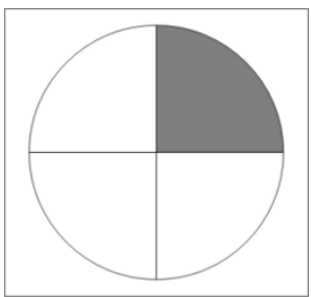

b)

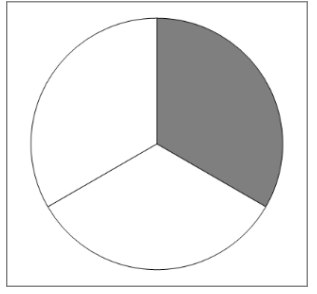

c)

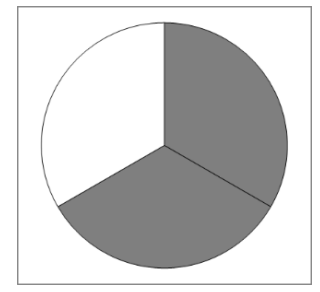

d)

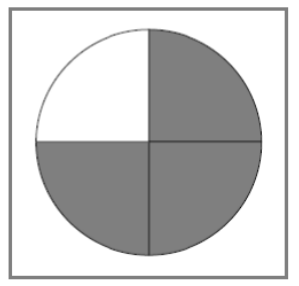

10. Which picture shows $\frac{1}{4}$ (one quarter) of the circle shaded?

a)

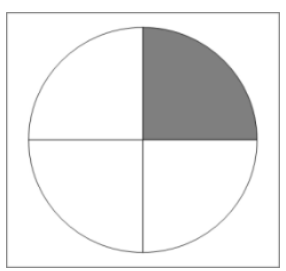

b)

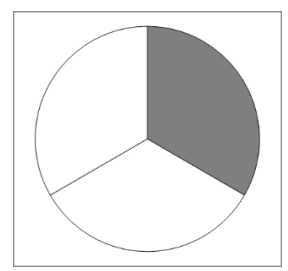

c)

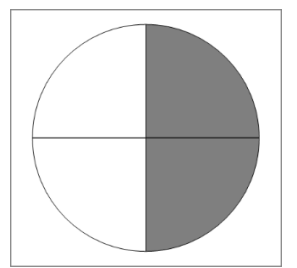

d)

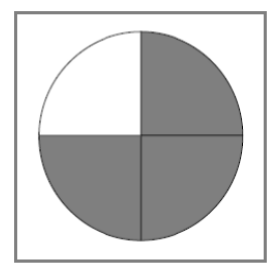

d)

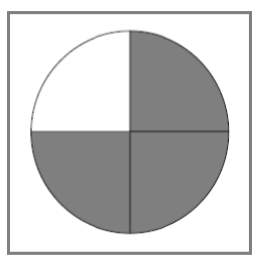

11. Which picture shows $\frac{2}{4}$ (two quarters) of the circle shaded?

a)

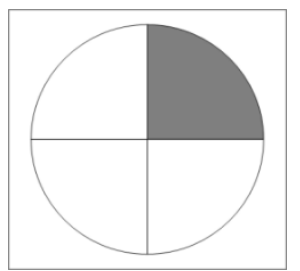

b)

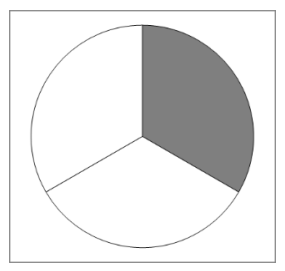

c)

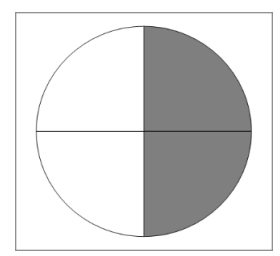

12. Which picture shows $\frac{3}{4}$ (three quarters) of the circle shaded?

a)

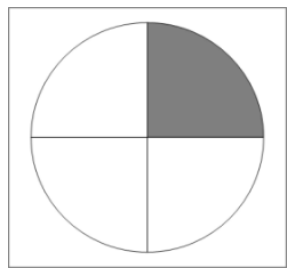

b)

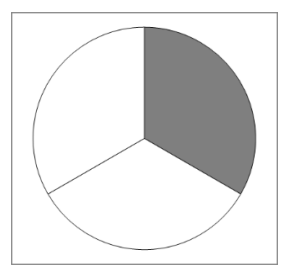

c)

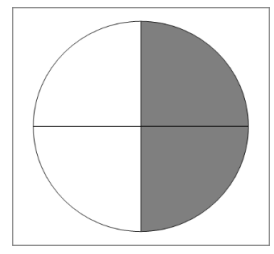

d)

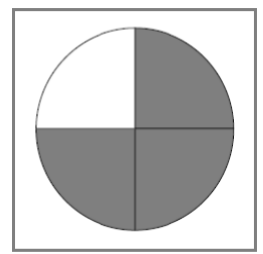


13. Which picture shows $\frac{1}{2}$ (half) of the ribbon shaded?

a)

b)

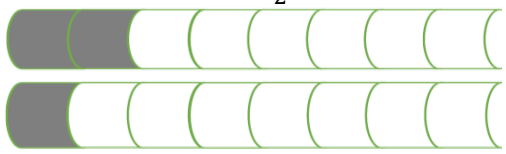

c)

d)

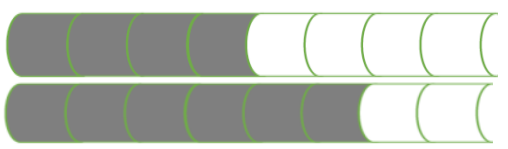

14. Which picture shows $\frac{1}{3}$ (one third) of the ribbon shaded?

a)

b)

c)

d)

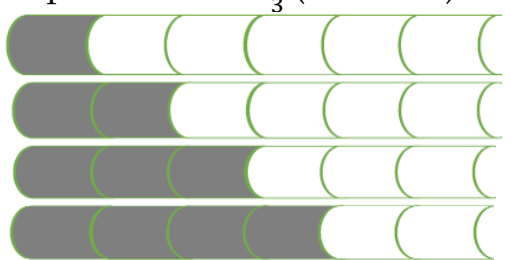

15. Which picture shows $\frac{2}{3}$ (two thirds) of the ribbon shaded?

a)

b)

c)

d)

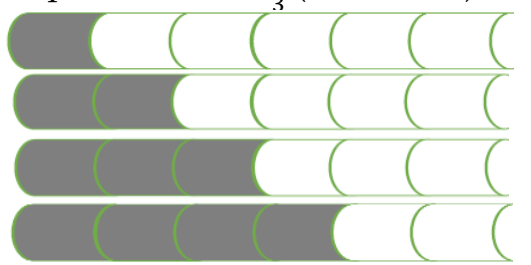

16. Which picture shows $\frac{1}{4}$ (one quarter) of the ribbon shaded?

a)

b)

c)

d)

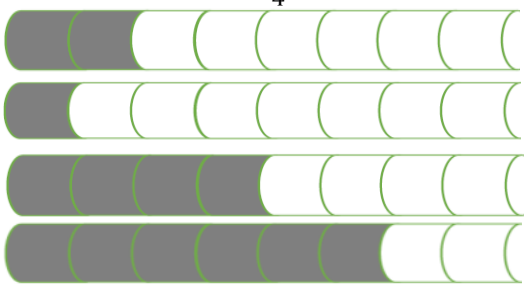

17. Which picture shows $\frac{2}{4}$ (two quarters) of the ribbon shaded?

a)

b)

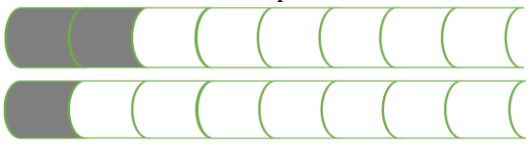

c)

d)

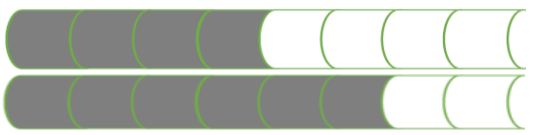

18. Which picture shows $\frac{3}{4}$ (three quarters) of the ribbon shaded?

a)

b)

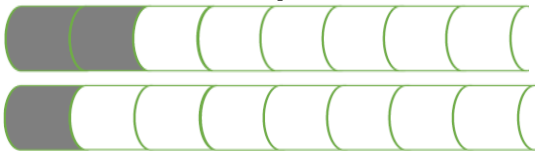

c)

d)

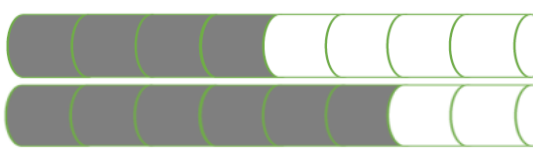


19. What fraction of this rectangle is shaded?

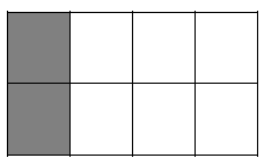

a) $\frac{1}{4}$ b) $\frac{1}{3}$

c) $\frac{1}{2}$ d) $\frac{3}{4}$

20. What fraction of this rectangle is shaded?

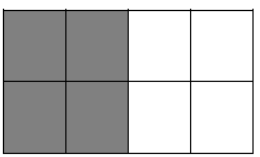
a) $\frac{1}{4}$ b) $\frac{1}{3}$
c) $\frac{1}{2}$ d) $\frac{3}{4}$

21. What fraction of this rectangle is shaded?

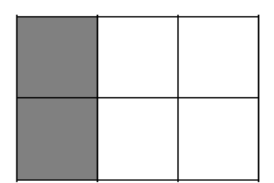
a) $\frac{1}{3} \quad$ b) $\frac{1}{2}$
c) $\frac{1}{4}$ d) $\frac{2}{3}$

22. What fraction of this rectangle is shaded?

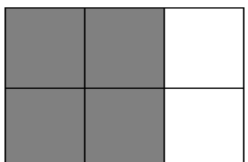

a) $\frac{1}{3} \quad$ b) $\frac{1}{2}$

c) $\frac{1}{4}$ d) $\frac{2}{3}$
23. What fraction of this circle is shaded?

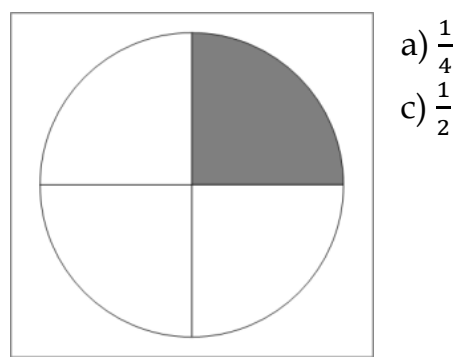

b) $\frac{1}{3}$

d) $\frac{3}{4}$

24. What fraction of this circle is shaded?

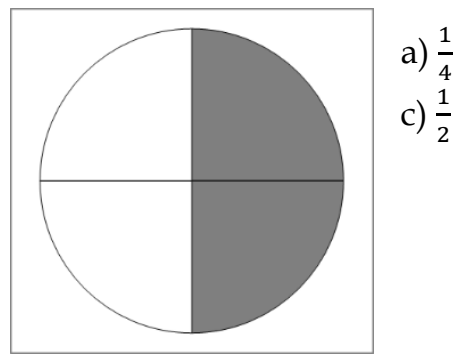

b) $\frac{1}{3}$

d) $\frac{3}{4}$

25. What fraction of this circle is shaded?

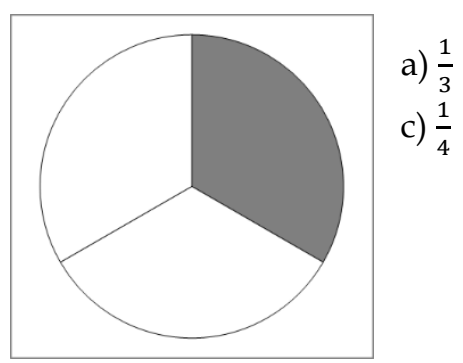

b) $\frac{1}{2}$

d) $\frac{2}{3}$

26. What fraction of this circle is shaded?

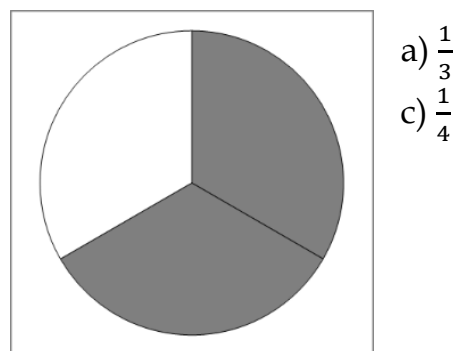

b) $\frac{1}{2}$

d) $\frac{2}{3}$ 
27. What fraction of this ribbon is shaded?
a) $\frac{1}{4}$
b) $\frac{1}{3}$
c) $\frac{1}{2}$
d) $\frac{3}{4}$

28. What fraction of this ribbon is shaded?

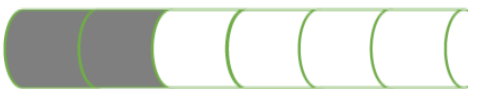
a) $\frac{1}{4}$
b) $\frac{1}{3}$
c) $\frac{1}{2}$
d) $\frac{3}{4}$

29. What fraction of this ribbon is shaded?

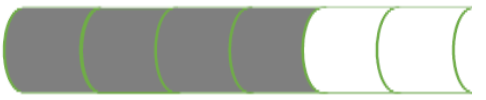
a) $\frac{1}{3}$
b) $\frac{1}{2}$
c) $\frac{1}{4}$
d) $\frac{2}{3}$

30. What fraction of this ribbon is shaded?

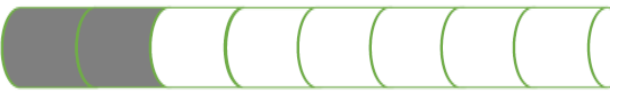
a) $\frac{1}{4}$
b) $\frac{1}{3}$
c) $\frac{1}{2}$
d) $\frac{3}{4}$ 